\title{
Thermal efficiency of a modified thermal storage wall containing phase change material in comparative test periods
}

\author{
Joanna Krason ${ }^{1, *}$, Lech Lichołai ${ }^{1}$ \\ ${ }^{1}$ Rzeszow University of Technology, The Faculty of Civil and Environmental Engineering and \\ Architecture, Poznanska 2, 35-082 Rzeszow, Poland
}

\begin{abstract}
The article presents the results and analysis of comparative tests carried out on a thermal storage wall modified with phase change material (PCM) in a selected time interval. These tests were carried out in real climatic conditions in external research chambers. The same transitional period has been compared, two consecutive calendar years, 2017 and 2018. The months of March and April were used for the analysis, which are characterized by large fluctuations of temperatures between day and night. Based on meteorological data for the Rzeszów-Jasionka station, the months of March and April are characterized by a longer period of sunshine and significant temperature fluctuations, which qualifies these months in the transition period for moderate climate in Poland. Selected physical parameters characterizing the influence of phase change materials on the thermal efficiency of a modified barrier were analysed. Analysis of selected parameters confirmed the repeated, beneficial effect of PCM on the stabilization of temperature in the internal space in selected research periods.
\end{abstract}

\section{Introduction}

In the construction sector, phase change materials are becoming more and more popular. In many scientific centres, theoretical and experimental tests confirm the beneficial effect of PCM materials on the stabilization of temperature in indoor rooms. In particular, those that are used, among others in external and internal barriers. The type and location of PCM in external walls depends on the climatic conditions in which these materials are used and on the structure of the outer wall itself. Article [1] presents the results of a year-long study of a wall modified with phase change material, which is part of a full-size room in a research building. The building was located in Shanghai, China. The modified wall was made of brick, in which $40 \%$ of the element was a composite including paraffin. The authors confirmed the beneficial effect of PCM on the stabilization of indoor temperature along with a reduction of about $24 \%$ of cooling in the summer and a $10-30 \%$ reduction in the demand for heating energy in the winter. In article [2] the authors, using the same research building and modified phase change material in the wall presented in article [1], focused on analysis in shorter time periods: from mid-March to mid-May, i.e.

\footnotetext{
*Corresponding author: jkras@prz.edu.pl
} 
in the inter-seasonal period and in the period from mid-June until the end of July, i.e. in the summer season. In the inter-seasonal period during external large temperature fluctuations, the fluctuation and maximum temperature on the inner wall surface was reduced.

A time shift in the maximum temperature in the room was observed, which affects the peak of the air conditioning load. In the summer period, no phase changes were observed in the PCM. This material remained in a liquid state. The maximum temperature values on the internal modified wall were higher than on the reference wall.

The authors of article [3] also confirmed the beneficial effect of PCM on the reduction of temperature fluctuations and the reduction of the maximum temperature in the tested room. The phase change material, enclosed in a panel made of aluminium with dimensions $10 \times 10 \mathrm{~cm}$, was installed on the outside of the building's wall. In the second variant, the PCM panel was placed on the inside of the room. The maximum room temperature was reduced by approximately $1^{\circ} \mathrm{C}$ and $2.3^{\circ} \mathrm{C}$ compared to the reference room.

Research on the influence of phase-change materials located in the barrier is also carried out in laboratory conditions [4-6] or using computer programs [7-9], and simultaneously comparing experimental and theoretical studies [10,11].

Phase change material is used in various wall structures, including those consisting of multiple layers. The authors of article [12] present the possibility of using PCM as one of the layers of a multi-layer outer barrier. The PCM layer is located between the outer layer made of cement board painted black, and galvanized sheet on the inside. The next layer from the inside of the room is a gap, and then the entire barrier is enclosed by a layer of cellular concrete. The purpose of the barrier constructed in this way is to improve the air circulation in the interior of the room. Two buildings were used in the tests in outdoor conditions, in which one of them was made of a wall with a PCM layer, to the southern side. The test results showed that the internal temperature in the building with the PCM modified wall was lower than in the reference building and there was a reduction in the flow of heat energy to the room of about $60 \%$.

In article [13], the authors proposed a passive solar barrier located on the southern side. The multi-layered wall is composed from the outside of board (sunlight board) of thickness $6 \mathrm{~mm}$, then the massive part of the barrier is a layer of concrete blocks of thickness $190 \mathrm{~mm}$ covered with a layer of PCM modified mortar from the outside and inside. The barrier has a vent gap between the board (sunlight board) and the wall layer, in order to circulate air in the interior of the room. The research was carried out by computer and experimental simulation. The results confirmed the effectiveness of using PCM, which in the period of lower temperatures contributed to an increase in room temperature. During cooling the temperature in the room with the PCM layer decreased more slowly than in the reference room. In article [14] the authors used microencapsulated phase change material, which was mixed with cement mortar. This layer is meant to be an alternative to a concrete wall in a multi-layer external barrier. Energy from solar radiation is obtained through a glazed layer, located on the outer side of the barrier. This energy is stored in a layer of cement modified with PCM. Then the energy is transferred with a delay to the ventilated gap between the storage layer and the insulation panel. There are ventilation openings in the panel that cause air circulation inside the room. Climatic data used for the study was taken from meteorological data from 4 days of November. The results highlight the time delay that occurs from obtaining solar energy to its transfer to the room. In this case, the cement layer was of thickness $4 \mathrm{~cm}$. It showed a time shift of four times shorter than in the case of a concrete layer.

The above examples of PCM applications lead to the possibility of its use in various structures of external barriers [15], as well as in thermal storage walls [16]. The climate occurring in the transitional period in Poland is characterized by significant fluctuations of external temperatures, which adversely affects the internal comfort of utility rooms in a building. 


\section{Experimental study}

The research was conducted in real climatic conditions in the area of south-eastern Poland, in the transition period for the month of March and April in two consecutive calendar years, 2017 and 2018.

One of the research chambers at the Rzeszów University of Technology was used for the research (Fig.1).

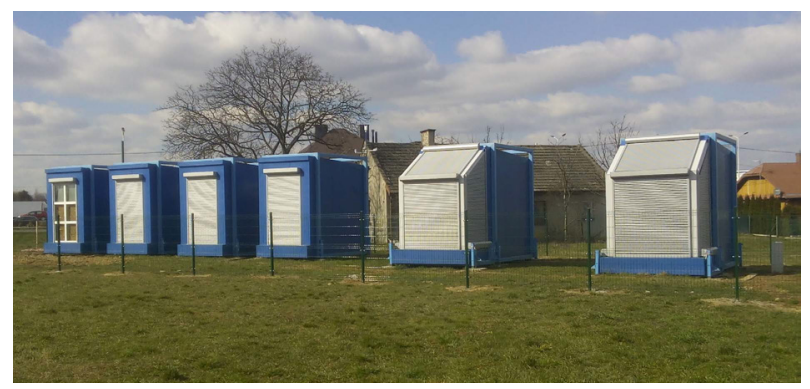

Fig. 1. View of the research chambers at the Rzeszów University of Technology.

The chamber has two thermal storage walls, directed toward the south. One of them was modified with a phase change material placed in the masonry layer. The barriers were separated from each other by a thermal insulation layer (Fig.2). The air in the test chamber was stabilized at $20^{\circ} \mathrm{C}$ to determine the heat flux density on the inner surface for individual barriers. External parameters were recorded in the analysed period on the same site. The parameters used were: total solar radiation and the outside air temperature.

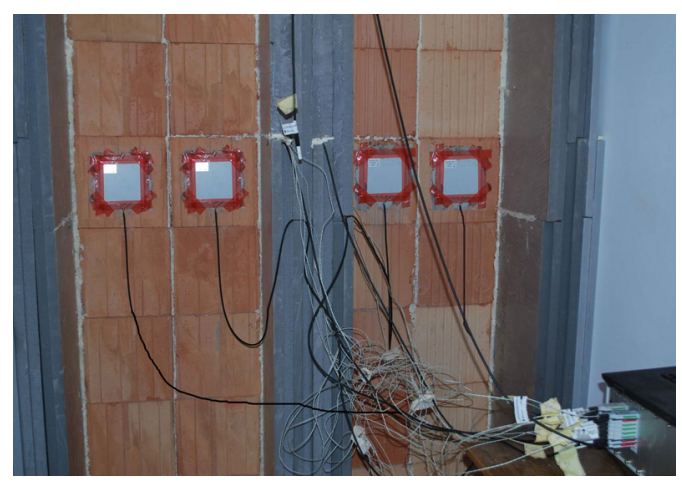

Fig. 2. Tested barriers in the chamber.

\subsection{Materials and methods}

For research purposes, two thermal storage walls were prepared, in one of which PCM was placed. Thermal storage walls were made of a glazing layer from the outside and a masonry layer, the basis of which was a ceramic block of thickness $260 \mathrm{~mm}$. In one of the research walls, the ceramic hollow block was filled with phase change material RT25HC. Paraffin was enclosed in a polyethylene film. PCM was placed in two rows of gaps from the outside of the ceramic hollow block (Fig.3). 


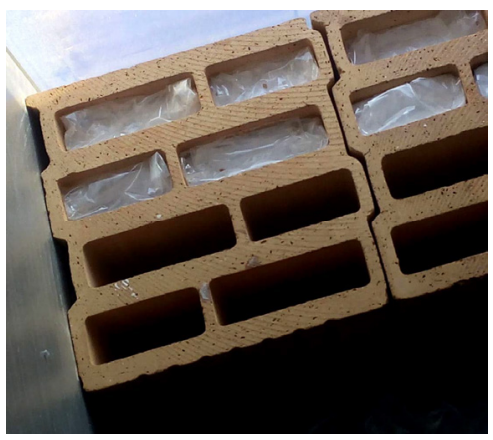

Fig. 3. Ceramic block with two slots filled with PCM.

To increase the accumulation of the masonry element the other two slots were filled with concentrated ceramic powder. To obtain only the effect of PCM on the flow of heat, in the reference wall, the ceramic block was completely filled with ceramic powder. Table 1 lists selected parameters of materials used in the barrier.

Table 1. Selected material parameters.

\begin{tabular}{|c|c|c|c|c|c|c|}
\hline Material & Density & $\begin{array}{c}\text { Thermal } \\
\text { conductivity }\end{array}$ & $\begin{array}{c}\text { Specific heat } \\
\text { capacity }\end{array}$ & Latent Heat & $\begin{array}{c}\text { Melting } \\
\text { temperature }\end{array}$ & $\begin{array}{c}\text { Coagulation } \\
\text { temperature }\end{array}$ \\
\hline & {$\left[\mathbf{k g} / \mathbf{m}^{3}\right]$} & {$[\mathbf{W} / \mathbf{m} \cdot \mathbf{K}]$} & {$[\mathbf{k J} / \mathbf{k g} \cdot \mathbf{K}]$} & {$[\mathbf{k J} / \mathbf{k g}]$} & {$\left[{ }^{\circ} \mathbf{C}\right]$} & {$\left[{ }^{\circ} \mathbf{C}\right]$} \\
\hline $\begin{array}{c}\text { RT25HC } \\
\text { solid } \\
\text { liquid }\end{array}$ & 880 & 0.2 & 2.0 & 230 & $22-26$ & $26-22$ \\
\hline $\begin{array}{c}\text { Ceramic } \\
\text { body }\end{array}$ & 885 & 0.266 & 1.0 & - & - & - \\
\hline $\begin{array}{c}\text { Brick } \\
\text { powder }\end{array}$ & 1418 & 0.185 & - & - & - & - \\
\hline
\end{tabular}

Glazing was used for the tests whose heat transfer coefficient was $0.6 \mathrm{~W} / \mathrm{m}^{2} \cdot \mathrm{K}$, and the total solar radiation permeability was $50 \%$.

The surface of the wall from the outside was covered with black paint to increase the absorption of solar radiation.

\subsection{Apparatus}

The tests used temperature sensors that were located inside the barrier at given measurement points. At the same time, plate heat flow sensors were placed on the inner surface of the barrier. All of the sensors were connected to a data logging system. Measurements were recorded every five minutes. The air temperature inside the chamber was also recorded, which was stabilized at $20^{\circ} \mathrm{C}$. The distribution of temperature sensors and heat flux is shown in Figure 4. 


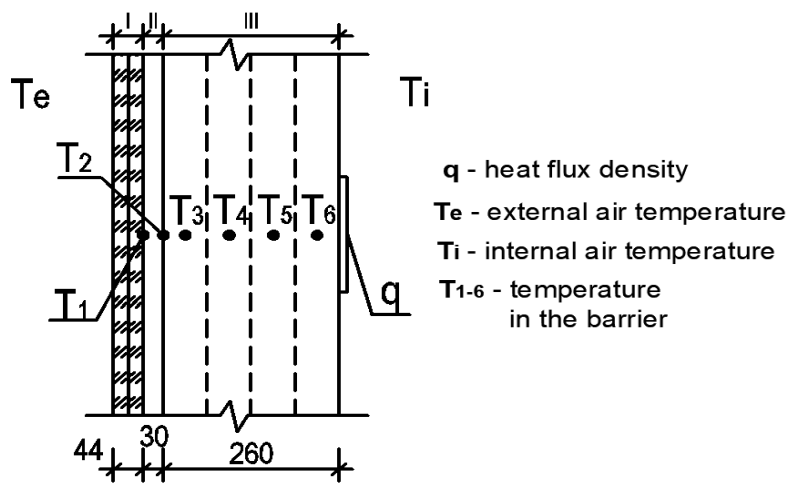

Fig. 4. Diagram of the test barrier. I-glazing, II-air gap, III-modified ceramic hollow block.

\section{Results and analysis of tests}

The studies compared two transitional periods, in two consecutive years, 2017 and 2018. Figures 5 and 6 show the temperature distribution in March and April 2017 and 2018.

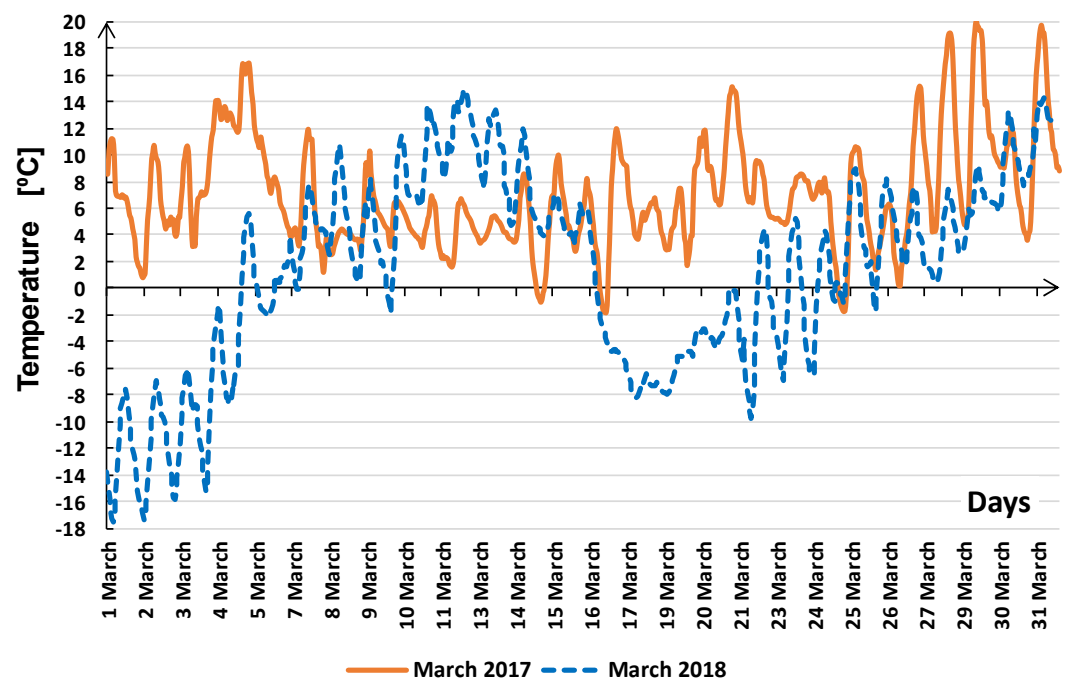

Fig. 5. Distribution of outside air temperatures - March 2017 and 2018.

In March 2017, most temperatures were positive in both day and night. The average daily temperature for this month was $10.5^{\circ} \mathrm{C}$, and at night $2.5^{\circ} \mathrm{C}$. The maximum temperature difference between day and night was $16.1 \mathrm{~K}$, and the average fluctuation value for the whole month was $8.3 \mathrm{~K}$.

Temperatures in March 2018 were characterized by lower values during the day and at night. The average temperature during the day in the month was $4.9^{\circ} \mathrm{C}$, while the night temperature averaged $-2.8^{\circ} \mathrm{C}$. The largest temperature difference between day and night was $13.9 \mathrm{~K}$, while the average value of temperature fluctuations was $7.9 \mathrm{~K}$, which is typical of the month of March of the previous year. These fluctuations may adversely affect the stabilization of the air temperature inside the building's interior.

Temperatures in the month of April in 2017 and 2018 differed significantly (Fig.6). 


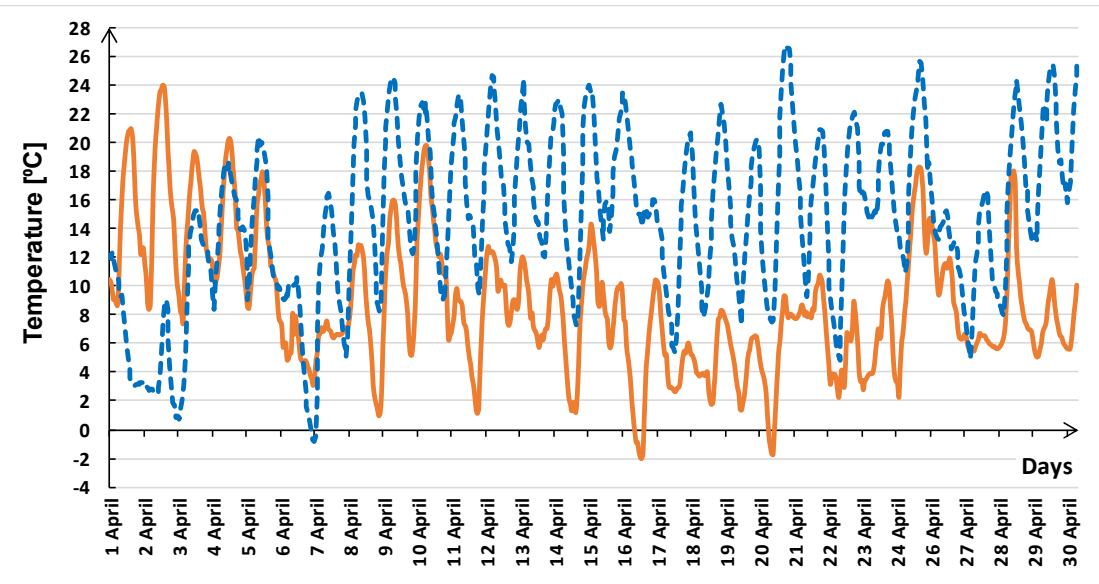

April $2017---$ April 2018

Fig. 6. Distribution of outside air temperatures - April 2017 and 2018.

In 2017, April was characterized by much lower temperatures than in 2018 . The daily average temperature of this month was $13^{\circ} \mathrm{C}$, while in 2018 the temperature was higher by $7.5 \mathrm{~K}$ and amounted to $20.5^{\circ} \mathrm{C}$. During the night, the average temperature in April in 2017 was $3.8^{\circ} \mathrm{C}$, while in 2018 it was $8.7^{\circ} \mathrm{C}$. The maximum temperature difference in April 2017 between day and night was around $15 \mathrm{~K}$, and $17.5 \mathrm{~K}$ in 2018 . Average temperature fluctuations amounted to 9.1 K for April 2017, and 11.9 K for April 2018.

Figures 7 and 8 present the distribution of total solar radiation in March and April 2017 and 2018.

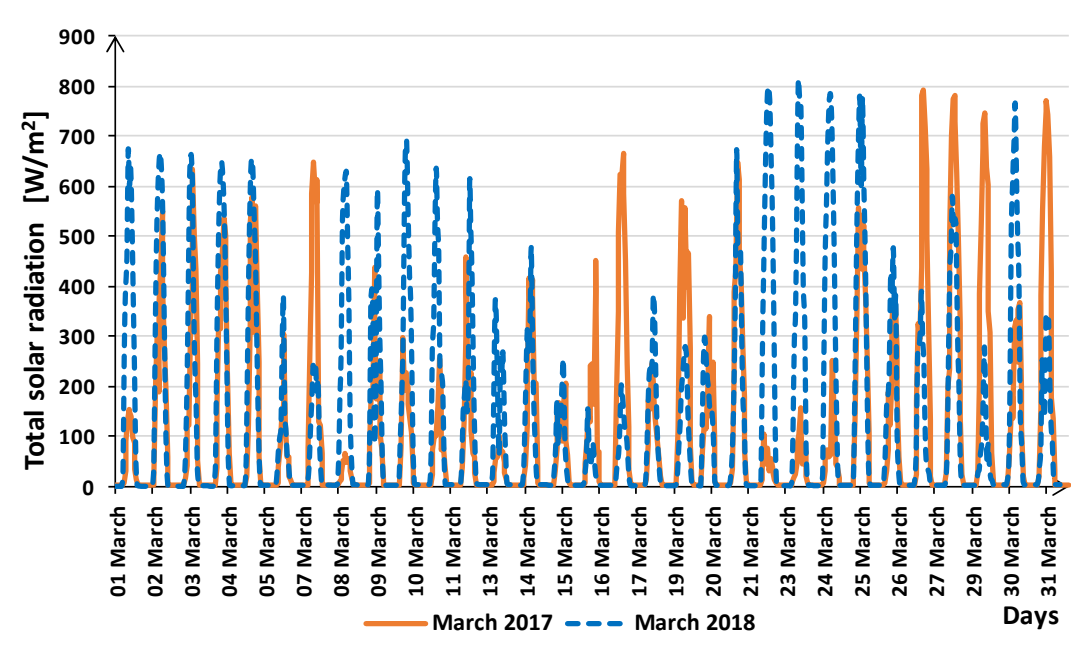

Fig. 7. Distribution of total solar radiation - March 2017 and 2018. 


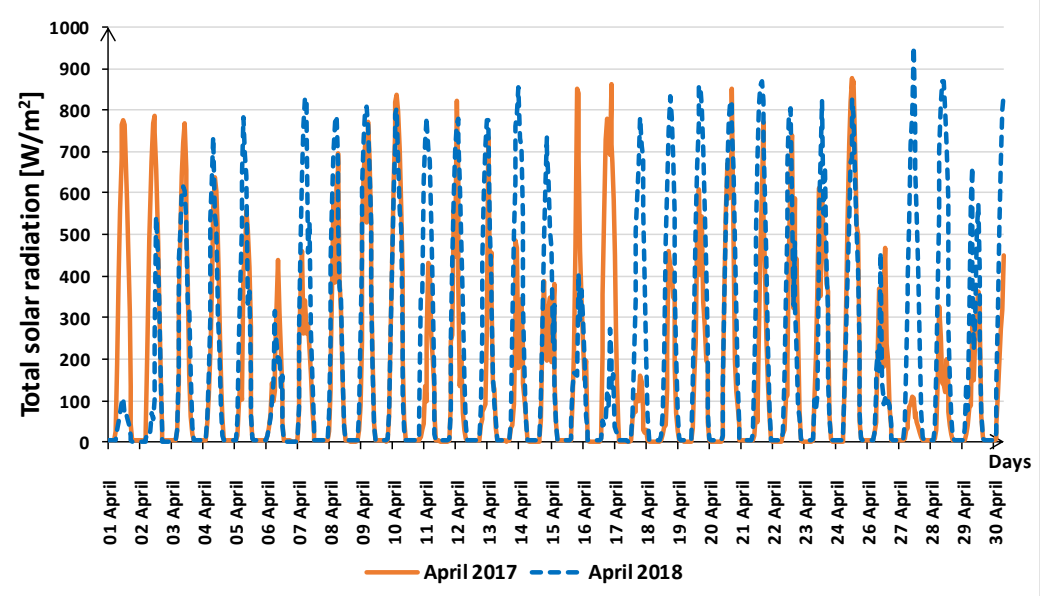

Fig. 8. Distribution of total solar radiation - April 2017 and 2018.

The maximum daily value of total solar radiation in the month of March 2017 amounted to $792 \mathrm{~W} / \mathrm{m}^{2}$, while in March 2018 it amounted to $812 \mathrm{~W} / \mathrm{m}^{2}$. In April 2017, the maximum daily value of total solar radiation was $878 \mathrm{~W} / \mathrm{m}^{2}$, while in April 2018 it was higher and amounted to $954 \mathrm{~W} / \mathrm{m}^{2}$.

Based on the recorded measurements, Figures 9-12 present the distribution of heat flux density values on the internal surface of the tested barriers in the comparative test periods. To analyse the heat flux density, the term "sunny day" was adopted as a day in which the daily average value of solar radiation was above $240 \mathrm{~W} / \mathrm{m}^{2}$, and a "cloudy day" as a day when the average value of solar radiation was below $240 \mathrm{~W} / \mathrm{m}^{2}$. This level was determined on the basis of the analysis of the amount of thermal energy that can be delivered to the PCM barrier, to ensure the optimal functioning of the thermal barrier.

Analysing individual research periods and referring to the characteristics of particular months in both years, it is possible to confirm the stabilization of heat flow in PCM modified barriers. This is most noticeable in a period occurring after at least three sunny days. In March 2017 (Figure 9), after the first sunny days in the month, the value of solar radiation decreased.

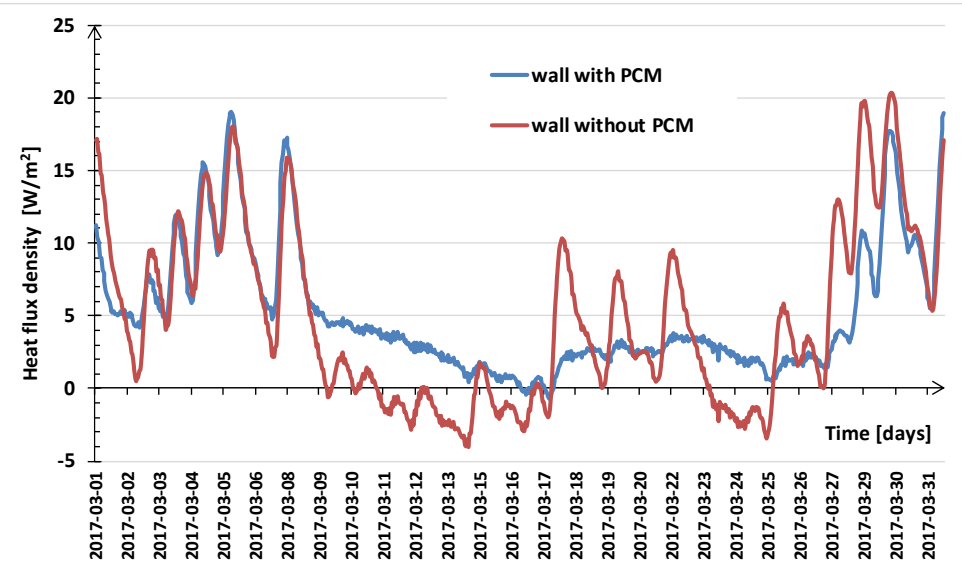

Fig. 9. Distribution of heat flux density on the internal surface of the barriers - March 2017. 
At that time, the heat flux density dropped sharply in the tested barriers. However, in the barrier without PCM, there was a further decrease in heat flow to the room, and then the heat flow changed towards the outer surface. On the other hand, in the barrier with PCM, the heat flow continued towards the interior of the room for the next days. Only after 7 cloudy days, in the wall with PCM were there small losses of thermal energy. During this period, the outside temperature did not exceed $10^{\circ} \mathrm{C}$ during the day.

In March 2018 (Fig.10), the distribution of heat flux density confirms the stabilization effect in a period of cloudy days, especially after a period of sunny days.

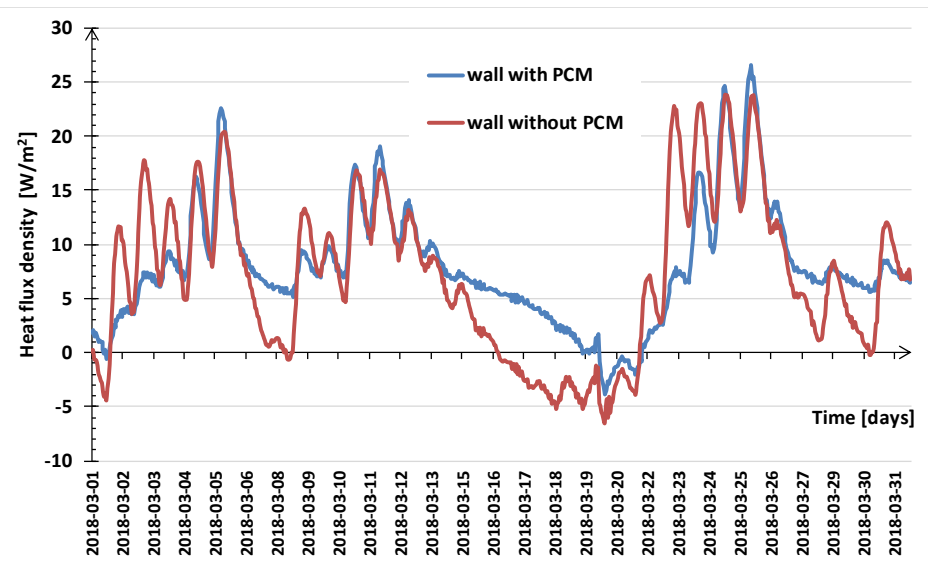

Fig. 10. Distribution of the heat flux density on the inner surface of the barriers - March 2018.

In this month, after a period of 7 cloudy days, with the outside air temperature dropping below $0^{\circ} \mathrm{C}$, a flow of heat in the outer wall occurred in the PCM wall. In the barrier without PCM, heat losses occurred after 3 days from the occurrence of cloudy days. In the above graphs (Fig.9,10) it was also shown that during a longer period of sunny days, in the first 2-3 days there is a significant increase in the heat flow to the room through the barrier without PCM. After 3 days, the heat flux density values are aligned in both barriers, and then a slight increase in the thermal energy flow occurs in the barrier with PCM, in relation to the barrier without PCM.

In Figure 11, the distribution of heat flux density in April 2017 confirms similar work of the PCM barrier as in the previous graphs, in the period in which similar external climatic conditions existed.

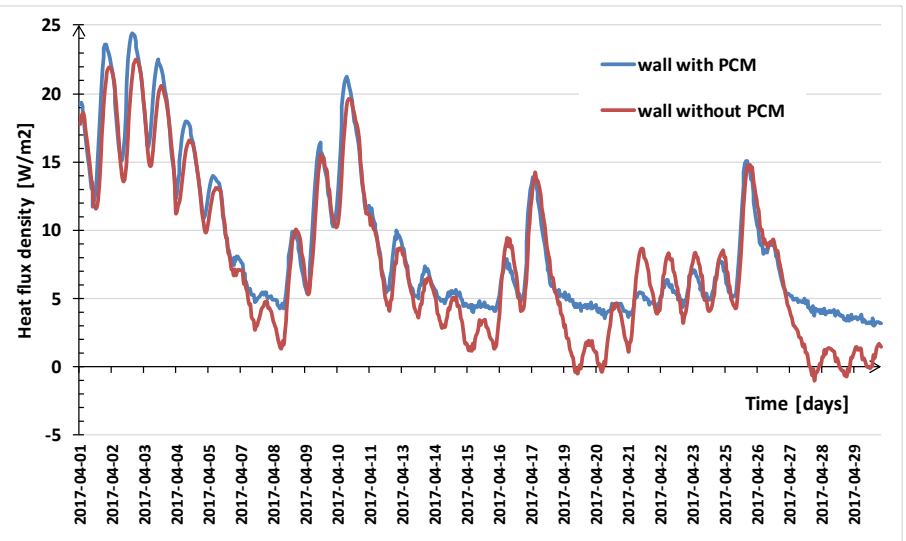

Fig. 11. Distribution of the heat flux density on the inner surface of the barriers - April 2018. 
In April 2018 (Figure 12), where there were a large number of sunny days and daytime temperatures were above $20^{\circ} \mathrm{C}$, a higher heat flux density to the room through the PCM barrier can be seen than in the case of a barrier without PCM.

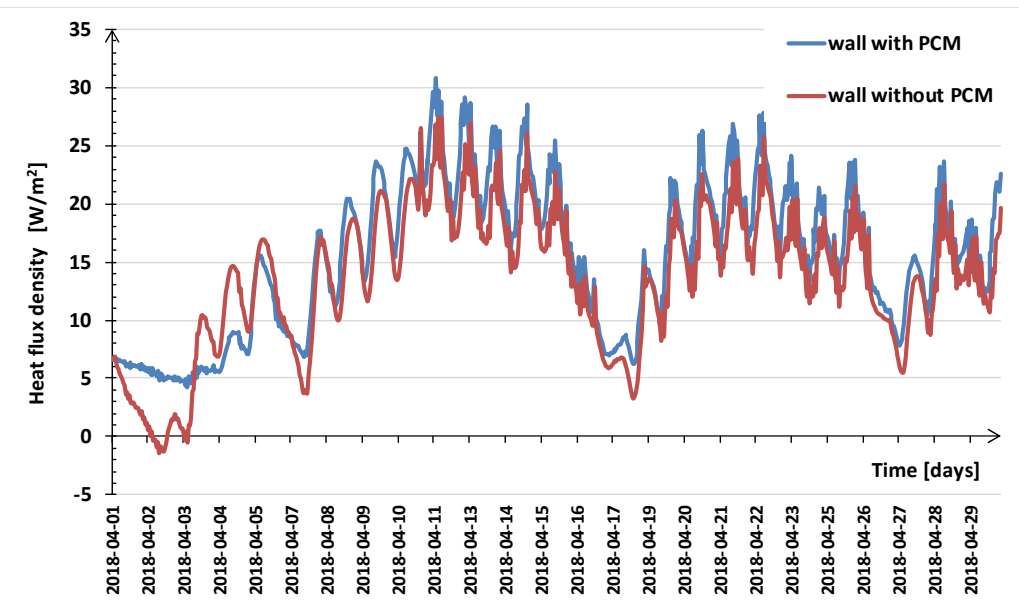

Fig. 12. Distribution of the heat flux density on the inner surface of the barriers - April 2018.

The maximum difference in heat flow flux between divisions was about $6 \mathrm{~W} / \mathrm{m}^{2}$. However, it should be noted that these values appear in the hourly range between 18.00 and 20.00 , which is advantageous in the transition period due to the lower temperatures in the evening and at night.

\section{Conclusions}

The article presents the analysis of the heat flux density distribution through a PCM modified barrier and a reference barrier without PCM, in given transition periods for the months March and April in two consecutive years, 2017 and 2018. On the basis of the conducted tests, a positive effect of the phase change material was confirmed for stabilizing the air temperature in the chamber, especially in the period in which there were significant fluctuations in the outside air temperature affecting the barrier. At the same time, the following conclusions were formulated:

- after 3 sunny days, in the case of consecutive cloudy days appearing in both barriers, the value of heat flow into the room decreases. However, in the barrier with PCM stabilization of heat flow occurs for about 7 cloudy days, while in the barrier without PCM there is a further decrease in heat flow, which may result in losses of thermal energy over a longer period, i.e. heat flow will occur in the external direction.

- in the case of alternating sunny and cloudy days, there are significant fluctuations in the thermal energy flow in the barrier without PCM, whereas in the barrier with PCM there are no significant disturbances in the heat flux flow.

- over 3 sunny days in both compartments there is an increase in the flow rate of the heat flux into the room. A slightly higher stream occurs in the barrier with PCM. The highest differences in the heat flux density values on the surface of the barriers occur between 18.00 and 20.00, which in the transitional season has a positive effect on the reduction of thermal energy consumption in the evening, with low ambient air temperatures.

In order to search the best effect of temperature stabilization in the considered wall in the long-term period, research are conducted on various quantitative solutions of PCM and its location. 


\section{References}

1. X. Wang, H. Yu, L. Li, M. Zhao, Energ. Convers. Manage. 120, 81-89 (2016)

2. L. Li, H. Yu, R. Liu, Build. Environ. 123, 494-503 (2017)

3. X. Kong, S. Lu, J. Huang, Z. Cai, S. Wei, Energ. Buildings 62, 597-604 (2013)

4. X. Wang, H. Yu, L. Li, M. Zhao, Energ. Buildings 126, 408-414 (2016)

5. L. Lichołai, A. Starakiewicz, J. Krasoń, P. Miąsik, Fizyka Budowli w Teorii i Praktyce 2, 19-24 (2018)

6. R. Vicente, T. Silva, Appl. Therm. Eng. 67, 24-34 (2014)

7. E. M. Alawadhi, Energ. Buildings 40, 351-357 (2008)

8. D. Heim, Renew. Energ. 35, 788-796 (2010)

9. D. A., Chwieduk, Energy 59, 301-313 (2013)

10. P. Principi, R. Fioretti, Energ. Buildings 51, 131-142 (2012)

11. T. Silva, R. Vicente, N. Soares, V. Ferreira, Energ. Buildings 49, 235-245 (2012)

12. P. Thantong, P. Chantawong, Enrgy. Proced. 138, 32-37 (2017)

13. D. Sun, L. Wang, Energ. Buildings 119, 183-188 (2016)

14. E. Leang, P. Tittelein, L. Zalewski, S. Lassue, Enrgy. Proced.122, 1009-1014 (2017)

15. L. Lichołai, M. Musiał, JCEEA, 63 (4), 329-338 (2016)

16. L. Lichołai, J. Krasoń, P. Miąsik, A. Starakiewicz, JCEEA 64 (1), 495-504 (2017) 